\title{
Emphasize on Niche Market Strategy for Attracting Foreign Tourists in Bangladesh
}

Md. Sajedul Islam ${ }^{1 *}$ and Iftakhar Hossain Jubery ${ }^{2}$

${ }^{1}$ Begum Rokeya University, Dhaka, Bangladesh

${ }^{2}$ Institute of Business Administration, IBA University of Dhaka, Bangladesh

\begin{abstract}
Bangladesh has bright prospects of travel and leisure in future. She possesses travel and leisure possibilities everywhere. But, Bangladesh travel and leisure is experiencing so many problems including technique. By applying specialized market techniques she can earn more Forex because Bangladesh is endowed with four key travel and leisure products: Seashores, Woodlands, Mountains and islands, traditional position and Historical sites those are mostly pleasing to many visitors. This document is focusing the existing pros and cons of travel and leisure market in Bangladesh and the ways to apply specialized market technique. Results indicate that four famous items can play essential part in the total income in this industry. Finally, this document indicates how specialized market technique will help the policy maker to distinguish the visitors market and customize their service to achieve ideal promotion goals and fix existing downwards income.
\end{abstract}

Keywords: Marketing; Marketing strategy; Niche market technique; Iconic items

\section{Introduction}

Bangladesh has bright prospects of tourism in future. She possesses tourism potentials all over the country. But, Bangladesh tourism is facing so many problems including marketing strategy. By applying niche market strategies she can earn more foreign currency because Bangladesh is blessed with four key tourism products: Beaches, Forest, Hills and islands, Historical place and Archaeological Sites that are mostly pleasing to many tourists. This paper is focusing the present strengths and weaknesses of tourism industry in Bangladesh and the ways to implement niche market strategy. Findings indicate that four iconic products can play significant role in the total earnings in this sector. Finally, this paper suggests how niche market strategy will help the policy maker to differentiate the tourists market and customize their service to achieve strategic marketing objectives and solve present downward earnings.

Today's travel and leisure market has become one of the most key elements in GDP participation in globally. It plays a significant part in socio-economic growth of a nation. Most of the visitors prefer to visit in different locations for different reasons (e.g. For Company, Research, Attend globally conventions, Holidays and holidays, Treatment, Meet with members of the loved ones, to see events like globe cup, Olympic etc.). It is recognized that most of the creating countries now generate financial benefits through its travel and leisure market. In past, the federal government may have been hesitant to invest for travel and leisure growth, but in this modern age the problem has changed. Now government focuses on not only travel and leisure but also kindness management like hotels, hotels, restaurants, transport, security and entertainment etc. Bangladesh as a creating nation is moving towards experiencing difficulties of globalization. It has beautiful attractions and historical places which are able to develop attention to globally visitors. But this market failed to develop effectively because of lack of maintainable and effective travel and leisure promotion techniques and hesitant attitude of different government authorities to develop this market. Many people from other countries have negative perception toward our nation. They feel Bangladesh is a nation of hardship, beggars, flooding and governmental anxiety. Besides, secretary of state for municipal aircraft and travel and leisure, Bangladesh Parjaton Organization (Govt. Tourism Organization) and other personal tour providers did not apply promotion idea and techniques effectively to reach their vacationer item to focus on consumers (tourists).

Bangladesh, as a location, has many aspects and strong points. She is gifted with almost all the natural possibilities that attract vacationer [1]. These include; Among beaches, Cox's Bazaar, the lengthiest unbroken clean and exotic seaside in the world; Kuakata sea seaside is known as sun rising and sunset; Sundarbans, the home of the spectacular Elegant Bengal lions, Rangamati, known as the heart of the spectacular pond district; Sylhet, known as the land of twelve religious Awuilia which amazing hills and tea gardens; Chittagong, the largest port town from the and known as the town of shrines; Above all, reverie beauty, vibrant tribe culture and simple town life are the primary aspects for getting traffic [2]. Though Bangladesh has lot of attractive locations but there are some weaknesses: poor facilities, volatile governmental scenario, image crisis etc. Besides, finance allowance on travel and leisure is not sufficient; market technique would be profitable way of Bangladesh. These kind of attractions are need to be researched by the internet promotion techniques and need to come up with and apply travel and leisure promotion ideal plan either by the Bangladesh Parjaton Organization (public sector) or the public-private areas both.

\section{Objectives}

The research goals of this research are:

1. To evaluate the promotion techniques implemented by Bangladesh Parjaton Organization.

2. To identify and evaluate the niches for getting competitive advantage as a globally location.

3. To suggest recommendations for the growth of key travel and leisure items in Bangladesh.

*Corresponding author: Md. Sajedul Islam, Begum Rokeya University, Dhaka, Bangladesh, Tel: +8801833181640; E-mail: sajidbru@gmail.com

Received March 18, 2016; Accepted April 25, 2016; Published April 28, 2016

Citation: Islam MS, Jubery IH (2016) Emphasize on Niche Market Strategy for Attracting Foreign Tourists in Bangladesh. Int J Econ Manag Sci 5: 337. doi:10.4172/2162-6359.1000337

Copyright: (c) 2016 Islam MS, et al. This is an open-access article distributed unde the terms of the Creative Commons Attribution License, which permits unrestricted use, distribution, and reproduction in any medium, provided the original author and source are credited. 


\section{Conceptual Framework}

\section{Reason 1: India's perception in the international community}

India's perception in the international community is not a very positive one, especially when it comes to safety. See for example, is it safe for a single American woman to travel in India? Many women have chronicled their experiences as being creepy, uncomfortable and unpleasant, to the extent of being dangerously close to sexual harassment. And this is an undeniable point. Even as a man, I have witnessed several such instances where men are clearly and unabashedly intrusive in the way they stare at women, or pass sexual comments. I remember a few years back when I was in Mumbai to meet my girlfriend and we took the local train at night. It was fairly crowded, and we got a couple of seats. A guy sat across from us and started staring at my girlfriend's chest. I noticed it and glared at him. He met my gaze, realized that he had been caught, and looked away. I didn't want to create a scene so I didn't say anything, hoping that it was over. But it wasn't. I caught him again, and then the third time. I lost my temper (not a good thing to do), caught him by the scruff of his neck and told him to get up and move away from the place. I was lucky that he was alone and that a middle aged gentleman who was aware of what was happening supported us and the guy had to move to the other end of the cabin.

Reason 2: Lack of basic tourism infrastructure like information centers, transportation etc.

At even the biggest Indian tourist spots, there is no way for someone who doesn't know the place or the language to get help and guidance. This obviously, is a hindrance to a lot of people. Plus, getting tickets in India is akin to winning a lottery. The only way people can safely travel is by air. And finally, the problem of taxis and auto rickshaws not being safe and overcharging customers is a big pain.

\section{Reason 3: Attitude of most Indians in the tourism industry}

Have you ever seen a rate card anywhere you travel? What has felt as the primary motive of all people related to the tourism industry travel guides, taxi drivers, shopkeepers, hotel owners etc.?

I can say that their primary motive is to make as much money as possible. They will try and overcharge customers whenever possible. I faced this when I visited Matheran and Munnar a couple of years back.

Naturally, I would avoid going to places where I am surrounded by people eagerly awaiting any opportunity to loot me. And mind you, these are not officials. They are just local people trying to make money. There is no organization in a large chunk of the country's tourism industry. As such, there is no accountability and or safety guarantee.

\section{Reason 4: Exploitation of "foreign" tourists}

Point 3 is even more of a problem for "white folks". All of these people (the tourism folks) assume that white folks are far richer and they have a special price (2-3 times higher) for foreigners.

\section{Reason 5: Lack of a proper "experience"}

When I visit a place, I do not want to know only the facts that I can easily Google or wiki. I want to understand, in depth, the history of the place and some fascinating stories from the past. I want imbibe the cultural nuances and savor the local flavors.

I want it to be a fun experience where the guide is knowledgeable about the place, can build a rapport with the tourists, and ensure that they have a great time.

\section{Reason 6: Poor planning and government involvement}

A few days ago, I was cleaning up the Indian Railways topic and I realized that we have a few tourist trains in India, the most famous being Palace on Wheels (luxury train). It covers the state of Rajasthan. We similarly have Maharaja Express that runs from Delhi to Agra (main attraction - Taj Mahal) and the Golden Chariot that covers Karnataka and Goa.

\section{Literature Review}

Though there are sufficient amount of literatures highlighting the marketing aspects of tourism, but a few of them has emphasized on the discussion of the promotional aspects of tourism marketing. At the same time, the literature attempted to deal with marketing aspects of tourism is not available enough especially, on the promotional issues of tourism marketing is much neglected and the literature on the same is very limited. In this study, the literature review includes the following: Chantarachoti described that in the eyes of foreigners Bangladesh is seen as a business destination rather than as a tourist destination when in actual fact there are potentials to explore in this country if properly promoted and promotion supported by government to the outside world. Also blamed that though Bangladesh has its abundant potential for growth of tourism industry could not utilized it properly due to lack of government support as well as the right initiatives of the country's NTO to highlight, Bangladesh to the eyes of foreigners as a tourist destination instead of a business destination. Though there are lots of similarities between India and Bangladesh and even with Nepal, Bangladesh is far behind from the mentioned two other countries due to the ineffective and insufficient promotional activities. He also claimed that the high foreign travel tax discourages foreigners to visit Bangladesh. Finally, he also emphasized that government's initiative can reduce the monopoly of the five star hotels by providing the facilities of establishing more hotels of different start and improving the infrastructure support, accommodation and land arrangements to promote and sell packages. Hasan described the present situation of Bangladesh tourism industry and present marketing strategies in his research book "Problems and Prospect of Bangladesh Tourism Industry" has blamed that Bangladesh tourism industry could not achieve the remarkable progress in comparison to other neighboring (South Asian) countries though the country is endowed with different tourism attractions. His criticism was concentrated mainly on the failure of Bangladesh Parjatan Corporation (BPC) to develop and lunch any dynamic and effective promotional strategy and then he suggested creating an independent and different organization for performing the marketing activities of BPC owned tourists spots. In addition to that he strongly recommended for initiating and implementing the marketing plan and strategy effecting for the potential markets and to avoid the aimless policies to develop mass tourism at the present stage in Bangladesh. Hossain and Firozzaman mentioned that Bangladesh tourism industry failed to grow properly not merely because it lacks in enough attractions but suffering mostly due to inadequate and effective promotional activities. They also claimed that the limited promotional materials like souvenirs, brochures, travel guides, accommodation guides, hand books, tourist maps, poster, folders, etc. distributed by BPC and some other private tour operators don't reach properly to the potential tourists and in addition to that, the quality of these materials is not satisfactory which causes not to create adequate curiosity among the potential tourists. At the same time, there are lacks in government initiative to offset or correcting the country's present image prevailing to the outside of the country as the country presently is suffering a lot from the image problem. The researchers also blamed 
that BPC or other private tour operators have little connection with the foreign tour operators and travel agencies for promoting Bangladesh tourism abroad though they act as hidden promoters of tourism activities in any tourist destination. According to the authors, lack of coordination among the parties related to tourism sector e.g. Ministry of Civil Aviation and Tourism, BPC, Biman Bangladesh Airlines, tour operators, travel agencies, hotels, other provides, local authorities and host population also causes for not developing the industry in Bangladesh. Mitra described that Bangladesh does not have enough effort to promote the country as a tourist destination. He argued that Bangladesh has to make aware to the tourists about what to see, where to stay and what to eat. He emphasized for the development of tourism industry, Bangladesh need to develop the infrastructure like hotels, resorts, promoting more places and there should have a link of the government tourism organization with the private sector to boost up the promotional activities for the same. Siddiqui, the Marketing Communication Manager, Pan Pacific Sonargaon Hotel, Bangladesh claimed that though Bangladesh has lots of things for tourism, but the country lacks in the initiatives to expose it to the potential tourists. $\mathrm{He}$ added that marketing communication can play an important role to let the people abroad to know what fantastic products Bangladesh can offer to the tourists. He emphasized on the cooperative efforts of the National Tourism Organization (NTO) with the private tour operators rather than emerging as the competitor for the overall development tourism industry. He also concluded that National airlines, hotels and the foreign missions of the country or at least an officer in each mission abroad with the responsibility of encouraging the potential tourists through providing necessary information and cooperation can contribute to a great extent for promoting the tourism industry of any country.

\section{Bangladesh Tourism Marketing Strategy}

Within marketing promotion mix elements, publicity appears to be the most useful form of promotional measures of the BPC. BPC also participate in international tourism exhibitions like the ITB at Berlin through which attractive package tours are sold to international tour operators and a large number of individual visitors in the fair. During tourism month (16 October - 15 November) different cultural night 36 shows, food festivals, seminars, symposiums, audio-visual presentations etc. are arranged mainly locally. BPC also uses a web page for disseminating the information to the potential tourists. But the fact is that the web page does not contain the complete information of Bangladesh tourism and it related facilities. As a result, it is tough for a potential tourist to have the required information from the said page. In the local market, BPC advertise in different newspapers, magazines, television and radio. BPC also sometime advertises in some specialized and special interest magazines. The private tour operators also lack of sufficient fund to operate an extensive promotional activities. As a result, they also conduct some promotional activities in a traditional form by distributing the brochures, leaflets, making advertisements in the local newspapers, participation of different exhibitions arranged locally. But a limited number of private tour operators prints and distributes their brochures in Bengali (local language), English and Japanese languages and some other operators do the same either in Bengal or in English or in both. There are some operators who participate in the international tourism fairs to attract the attention and encourage the potential tourists and try to sell package tours to the foreign tour operators as well as to the individual tourist. This sort of participation helps to get the media coverage in the international level. But most of the private tour operators try to attract the local nationals and the foreign residents already living in Bangladesh or visiting Bangladesh. The private tour operators also use some sorts of sales promotion like off-season price discounts, free distribution of printed materials; organize live music programs for the visitors in destination's spot, extra service offers, group tour discounts for the packages offered and river cruise programs. Hardly two or three operators are using the web page for the promotion of the tourism in Bangladesh. Therefore, the objectives of the tourism marketing strategy in Bangladesh are now outlined:

- To consolidate Bangladesh's position as a tourist destination in the established generating markets at regional and international levels by utilizing different marketing tools such as websites;

- To target new and potential markets by identifying and monitoring changing designs and needs for various market types such as China, Japan, East European and South America, and South Asian countries;

- To enhance Bangladesh's competitive position in the intercontinental destination market by mobilizing effective promotional measures supported by attractive proposals and appealing tourism products; and

- To pay special attention (in terms of promotion and product diversification strategies in particular) to tourist arrivals from Europe, South Asia, USA, Gulf Coop.

\section{Marketing Strategy}

Marketing method is the outcome of a firm's segmentation, focusing on and placement choices (STP process) at the quality of the Strategic Company Unit [3]. This viewpoint is reinforced by promotion books (for example, Kotler, [4], where this procedure is required as the core of technique. In other words, the primary idea of technique involve the tasks of determining and choosing the focus on sections in where the actual and prospective clients are living and desired to purchase the item. In advanced stage, there are three technique, market segmentation, focusing on and placement in reaching minds of the focus on clients and offer them suitable products/services that will serve clients special interests. The term "segmentation" appears to have been initially introduced by Cruz. According to Kotler [5], market segmentation means splitting the whole market into different parts on the basis of various factors. Target Marketing involves breaking market into sections and then focusing promotion efforts on one or a few key sections. According to Kotler et al. placement is the way the item is described by visitors on essential attributes; it is the position the item consumes in tourists' mind relative to competitive items.

\section{Niche market strategy}

Niche promotion has been used synonymously with "market segmentation", "target marketing", "micromarketing" "regional marketing", "focused marketing" and "concentrated marketing" [6,7]. It is, however, none of these and all of these. From an overall firm technique viewpoint, a specialized market method described as "a focus on a particular need, or geographical, market or item segment" [8]. Kotler states that niches are usually constructed by splitting a section into sub-segments and that the key issue in internet promotion is expertise. Shani and Chalasani [9] distinguish between market segmentation and internet promotion. They define market segmentation as a top-down approach. A literary works search by Kara and Kaynak [10] came to the conclusion that internet promotion takes 
market segmentation one step further in terms of creating a unique group of clients.

Here are four simple strategies your tourism business can consider to bolster your appeal overseas.

Think eco-tourism/adventure travel: Canada is emerging as a global destination for eco-tourism and adventure travel. The country is a natural draw for international visitors seeking authentic wilderness, adventure and cultural experiences. Canada has a reputation as an uncrowned and unspoiled holiday destination with a wide diversity of wildlife. Its natural environment also appeals to visitors seeking an adrenaline rush with such activities as windsurfing, white water kayaking, skiing and rock climbing. Consider how you can take advantage of the eco-tourism and adventure travel opportunities in your area. Even if your business is urban based, you can appeal to foreign visitors simply by helping them find local eco-tourism activities.

Give your website global reach: You can benefit from customizing your website to your target market with simple visual aids such as country flags. Showing your prices in local currency can help you connect with international visitors and increase their ability to compare prices. In the end, you want to increase user confidence and comfort. As well, it's important to provide international travelers with basic information on Canada, such as weather, currency, local customs and cuisine.

Make your business multi-seasonal: Any tourism operator today knows that building an all-season capacity into your business drives growth and revenues. And this is particularly important for attracting international visitors. If you're looking for ways to make your business an all-season affair, the first step is to assess the potential year-round activities in your area. Are there cultural activities, such as music festivals, that would attract visitors? Are there seasonal outdoor activities year round? You might consider adding a new dimension to your tourism business, such as offering spa services in the winter season.

Consider exhibiting at tradeshows: It's a marketing rule of thumb: Person-to-person contact can generate sales. And that's precisely what attracts thousands of tourism businesses and travelers to international tradeshows. If you're shopping around for a tradeshow to exhibit your business, ensure that you choose one that gives you the best exposure and avoid untested venues. As well, prior to the show, be sure that your trade show team is properly trained to sell your business.

\section{Methodology}

To achieve the goals of the study mainly the additional details has been used for performing this analysis. Secondary details has been gathered from yearly reports, website of secretary of state for municipal aircraft and travel and leisure and Bangladesh Parjaton Organization, publications of globe trade companies, different publications and analysis documents. After collecting details scientists evaluate the prospective buyers of nice market technique for the development of travel and leisure market in Bangladesh.

\section{Findings and Analysis}

\section{Market segmentation}

Market segmentation technique performs a natural part in the achievements of travel and leisure promotion goals. A vacationer market may be recognized corresponding to each vacationer item. In that sense, we can determine companies are a set of actual and audience of each item. There are five segmenting variables: Geographical, Market, Geo-demographic, Psychographic and Behavior [11]. Bangladesh Parjaton Organization (BPC) creates the plan to control the travel and leisure market. To segmenting the focus on audience it highlight on two factors that are (i) Market segmentation and (ii) Psychographic segmentation. Market segmentation are usually huge because in that section vacationer item can entice a small variety of categories and age provides the biggest range of options for interpreting a huge amount of categories. Psychographic segmentation provides us detail details of visitors. By this segmentation could about tourists' personal passions, inspirations, ambitions and feelings etc.

(i) Demographic segmentation for worldwide tourists:

- $\quad$ Ethnic identification and nationality: Most of the visitors arriving from European nations, Southern Japan, USA, Beach Collaboration Authorities Countries, Eastern Japan and the Hawaiian Rim, USA, Britain, Sydney and New Zealand and others.

- $\quad$ Age: Tourists categories are usually young and middle age people; sometimes families with kids and even pensioners are arriving too frequented at different places.

- $\quad$ Family life cycle: Some Bangali UK and USA immigration like to check out Bangladesh with their kids to familiar about culture and its culture.

- Sex: Men and women both equally like to check out Bangladesh.

- Religion: Muslims, Buddhists' and Christian pilgrims are interested in their concerned spiritual websites in Bangladesh.

(ii) Psychographic segmentation for worldwide tourists:

Actually demographic segmentation deal is vast and clear and understandable but the factors of psychographic segmentation is so detail that is needed to understand more about. The living design, day to day activities and the enjoyment item absorbed by the visitors is most essential. For psychographic segmentation customer's special passions, activity, views, and behavior towards different types of holidays is significant. Therefore, BPC is trying to segmenting the marketplace on the reasons for tourists' psychographic features but not success. If they could distinguish among these sections, they would be able to select appropriate sections and create as well as apply technique for each selected focus on team.

\section{Target marketing}

Target promotion involves evaluate each market section attraction and selecting one or more sections to enter. In that stage BPC focus its promotion effort on Seashores, Mountains \& isles, Woodlands \& Forest, Traditional places, Historical Sites and other.

\section{Market positioning}

According to kotler et al. placement is the way the item is determined by visitors on essential attributes; it is where the item consumes in tourists' thoughts relative to competitive items. It is difficult to enhance specific visitor's item when that item have several attraction. That's why BPC enhance package of tourist's item for the visitors. According to data of MoCAT, BPC consider four major tourist's items that have attraction and demand and added competitive advantage to Bangladesh. Those items, won good placement in the visitors thoughts in the European nations, Southern Japan, Eastern 
Japan and the Hawaiian Rim, USA, Britain, Sydney and New Zealand and the goods are as following:

1. Beaches

2. Forest, Mountains and isles

3. Historical position

4. Archaeological Sites

Niche sell for beaches: The Seashores item variety contains Patenga, Parki, Cox's Bazar, Teknaf, St. Martin Island and Kuakata. Among these Cox's bazaar, Teknaf and St. Martin have more regional and worldwide visitors. The visitors who want to keep relax, save from mental problem, health and fitness for body disorders and check out for open air are especially focus on team [12].

Niche sell for woodlands, mountains and islands (Eco-tourism): Mountains and Islands contain Sundarban (the home of the spectacular Elegant Bengal tigers), Rangamati (the pond district), Kaptai (the pond town), Bandarban (the roof of Bangladesh) and Khagrachhari (the hilltop town). Tourists who are looking for naturel and different societies of different tribes' everyone is especially focus on team. These websites covered visitors eco-tourism needs. So Bangladesh ecotourism met the eye of focus on team.

Niche sell for traditional place: Mostly drawn historical position contains National Art gallery, Central shahid Minar, Curzon Area, Martyred Perceptive Funeral, Baldha Garden, Subrawardy Uddayan, World War II Graveyard, Old high Court Building, Nator-Rajbari etc. Bangladesh has rich record about its culture. Tourists who want enhance their information about record are especially focus on team.

Niche sell for historical sites: Mostly drawn archaeological websites are Mainamati, Paharpur, Shait Gombuge Mosque, Kantajis Forehead, Lalbagh Citadel, Sonargaon, Ahsan Manzil etc. Tourists (researchers and students) who want enhance their information about the archaeology of gortyn are especially focus on team. This item met the eye of focus on team [13].

\section{Recommendations and Conclusion}

Bangladesh is a developing country and it has lots of tourist's items but all goods are not gaining worldwide visitors. So Bangladesh needs to focus to create Famous items rather than to enhance the variety of offers. The following suggestions will help to the ability to create its four Famous Products: First of all, for beaches power should set up more resorts, resorts and security. Authority can encourage natives to take part for their own economic benefit. Local power should update the features of beach websites. Secondly, for eco-tourism power should secure the green environment and forest also. Local power should effort to involve tribal's in the process of eco-tourism. Additionally, for historical position power should enhance its historical places and promotion these places through marketing mix. It is essential to protect historical places. Lastly, for archaeological websites power should create interaction (transportation) features to reach these websites and set up standard hotel and restaurants closest to websites. It is necessary to train up the human resources of different websites workplace to guide the worldwide visitors properly. It is necessary to offering the key items to niches in different way in compare to competitive nations. By taking proper internet technique Bangladesh can improve the invoices and variety of visitors. Specialized market technique can be useful because most of the worldwide visitors have attention to check out the above mentioned websites and willing to keep few days and spend cash for their enjoyment. By applying this tactic BPC can distinguish its tourist's item for different focus on categories (need basis) and secure it's downwards income.

Finally, the results of this analysis will help the plan maker to apply market way to serve the focus on sub multiple worldwide visitors. By using skilled private trip providers it can have more worldwide visitors to check out its four key items Seashores, Eco-tourism, Traditional position and Historical websites in addition to marketing program, set up vacationer workplace in overseas and modified websites.

\section{References}

1. Shahid M (2004) The tourism fair contributors to Bangladesh Economy', Holiday Aviation, August 31 $1^{\text {st }}$, Dhaka Bangladesh.

2. Hasan SR (2005) Marketing publicity and sales promotion for tourism development in Bangladesh Social Science Review 19, No. 2, Dhaka University, Bangladesh.

3. Webster FE (2005) Back to the future: integrating marketing as tactics, strategy and Organizational culture. Journal of Marketing 69: 4-6.

4. Kotler P (2003) Marketing Management (11thedn), Prentice-Hall, Upper Saddle River, USA.

5. Kotler P (2000) Marketing Management (11thedn), Pearson Education, Inc., NJ

6. Dalgic T, Leeuw M (1994) Niche marketing revisited: concepts, applications and some European cases. Eur J Mark 28: 39-55.

7. Linneman RE, Stanton JL (1992) Making Niche Marketing Work: How to Grow Bigger by Acting Smaller, McGraw-Hill, Inc., New York, USA.

8. Teplensky JD, Kimberly JR, Hillman AL, Schwartz JS (1993) Scope, timing and strategic adjustment in emerging markets: manufacturer's strategies and the case of MRI. Strategic management journal 14: 505-527.

9. Shani D, Chalasani S (1992) Exploiting niches using relationship marketing The Journal of Services Marketing 9: 33-42.

10. Kara A, Kaynak E (1997) Markets of a single customer: exploiting conceptual developments in market segmentation. Eur J Mark 31: 873-895.

11. Kotler P (1991) Marketing Management (7thedn), Englewood Cliffs, New Jersey: Prentice-Hall.

12. Saunders J (2002) Quantitative methods in marketing, Thomson, London, pp 85-99.

13. Smith WR (1956) Product differentiation and market segmentation as alternative marketing. American Marketing Association 21: 3-8. 